\title{
International Physicists' Tournament 2016: the origins of EmSci
}

Daniel Suchet

Emergent Scientist Editor-in-Chief

emergent.scientist@edpsciences.org

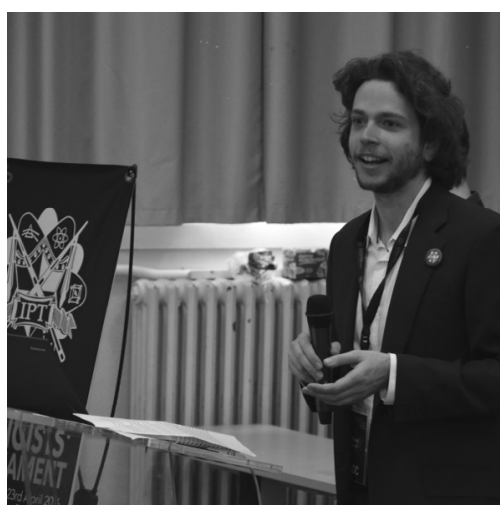

articles published in the journal". For many of us, it was also an opportunity to discover the publishing world from behind the scene - Emergent Scientist (Em. Sci.) is not only a training course in scientific reading and writing, but also in reviewing and editing.

The IPT 2016 has been the cradle of Emergent Scientist, and logically provided the material for its first volume, which you are about to read. We received almost 20 manuscripts, and it has taken some time to tailor appropriate assessment criteria for reviews, write didactic reports to guide authors through revisions, and prepare the structure of the journal. In the name of the whole editorial board, I want to thank especially the IPT participants for their enthusiastic support and patience.

A year has passed since we began preparing this first volume. Today, we are not only releasing solutions to the exciting problems of the IPT, we are starting a new way to bring the whole publication process - reading, writing and reviewing - straight to young scientists. A second volume, dedicated to the IPT 2017, is on its way and the first generic physics issue, open to any submission, will be open soon.

Spread the word! Tell your friends and colleagues, tell your students and teachers: Emergent Scientist is meant for you to use it, and we are going to need your support and input to make the best out of it. 